\section{Physiological and Morphological Traits Associated with Increased Water Use Efficiency in the Willow-leaf Peach}

\author{
D. Michael Glenn ${ }^{1}$, R. Scorza ${ }^{2}$, and C. Bassett ${ }^{3}$ \\ U.S. Department of Agriculture, Agricultural Research Service, Appalachian \\ Fruit Research Station, Kearneysville, WV 25430
}

Additional index words. apparent root surface water potential, isotopic carbon discrimination, peach breeding, Prunus persica, water stress

\begin{abstract}
A chimeric, willow-leaf mutation of a standard peach [Prunus persica (L.) Batsch.] phenotype was evaluated for its water use efficiency (WUE). The willow-leaf phenotype had greater WUE than its standard-leaf parent under both nonstressed and well-watered conditions, and this was supported by isotopic carbon discrimination. Under water-stress conditions, willow-leaf trees developed less water potential gradient from the roots to the leaves. The mechanisms associated with increased WUE by the willow-leaf phenotype include a reduced water potential gradient within the plant and uncoupling of the leaf from the aerial environment. Willow-leaf peach trees in seedling populations, descended from a different willow-leaf parent, also had reduced carbon isotopic discrimination than did sibling standard-leaf seedlings.
\end{abstract}

In water-limited environments, drought tolerance and effective use of water are critical to productive fruit production where fruit size is the main component of quality. Bongi et al. (1994) demonstrated that, within a range of interspecific hybrid rootstocks there was great variability in carbon isotope discrimination $(\Delta)$, and that this was correlated with water use efficiency (WUE) and yield. Leaf photosynthetic rate and other properties were not related to WUE; however, the most vigorous plant material transpired the least and had the highest WUE. Others have demonstrated that WUE is correlated with $\Delta$ (Farquhar and Richards, 1984; White et al. 1990). Glenn and Scorza (1992) evaluated reciprocal grafts of standard and dwarf peach types and found, as did Bongi et al. (1994), that the phenotype and growth characteristics of the scion were independent of the rootstock. Cytokinin-like activity and auxin levels in xylem sap were higher in dwarf than in tall phenotypes and the tall, vigorous phenotypes had lower resistance to water flow, and, presumably, greater transpi-

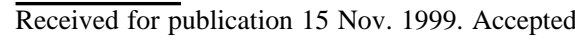
for publication 10 Mar. 2000. We thank W.B. Sherman for providing 'Early Amber' and the willow-leaf chimeral mutant, W.R. Okie for the seed of the segregating willow-leaf populations, and $\mathrm{C}$. Cavin and M. Demuth for assistance in data collection. Use of company or product name by the U.S. Dept. of Agriculture does not imply approval or recommendation of the product to the exclusion of others which also may be suitable. The cost of publishing this paper was defrayed in part by the payment of page charges. Under postal regulations, this paper therefore must be hereby marked advertisement solely to indicate this fact.

${ }^{1}$ Soil Scientist. To whom requests for reprints should be addressed. E-mail address: mglenn@ afrs.ars.usda.gov

${ }^{2}$ Research Horticulturist.

${ }^{3}$ Molecular Biologist. ration rates. To better understand the role of transpiration in growth of peaches, we studied the transpiration and carbon assimilation characteristics of a standard-leaf peach cultivar and its chimerical mutant, a willow-leaf type. Because these two phenotypes apparently differ only in a single-gene mutation in the $\mathrm{L}_{1}$ layer of development (W.B. Sherman, personal communication), and have different leaf types, the effect of the willow-leaf character on WUE could be evaluated in a uniform genetic background, thus reducing genotype $x$ environment interaction.

\section{Materials and Methods}

Lesley (1957) first identified a willow-leaf peach, a phenotype characterized by its narrow leaf width. The plant material of this study was a standard-leaf peach, 'Early Amber', and its willow-leaf chimeral mutation obtained from W.B. Sherman and bud-grafted to 'Lovell' rootstock. Six trees of the willow-leaf phenotype and six of the standard-leaf phenotype were grown in 40-L containers with a silt loam soil for 3 years in the greenhouse and then transplanted to the field. The 'Early Amber' willow-leaf character was not genetically transmittable, and therefore is probably a $\mathrm{L}_{1} \mathrm{mu}$ tant. A second source of willow-leaf was found in a seedling rootstock obtained from W.B. Sherman and proved to be transmittable. This genetic source was used to generate segregating seedling populations.

Growth chamber studies. Six trees each of the standard phenotype and its willow-leaf mutant phenotype were grown for 3 years prior to the growth chamber studies. The trees were assigned a paired arrangement prior to the studies. At the time of the study, the standard-leaf trees were larger in canopy volume than the willow-leaf trees; standard trees were $\approx 1.5 \mathrm{~m}$ high and $1 \mathrm{~m}$ wide while the willow- leaf trees were $1 \mathrm{~m}$ high and wide. Canopy carbon assimilation was measured by placing an individual tree into a sealed chamber $(1.2 \times$ $2.4 \times 1.8 \mathrm{~m})$ and measuring the depletion of $\mathrm{CO}_{2}$ in a specified range (330 to $350 \mu \mathrm{L} \cdot \mathrm{L}^{-1}$ ) using a Beckman Infrared Gas Analyzer (Model 865; Beckman Instruments, Fullerton, Calif.) that measured the $\mathrm{CO}_{2}$ levels of recycled air. In these studies, the 40-L root volume was sealed in a plastic bag and the entire tree suspended on a load cell to record the loss of water due to transpiration. Chamber temperature was constant at $18{ }^{\circ} \mathrm{C}$, relative humidity (RH) was $60 \%$ to $70 \%$, and photosynthetically active radiation $(P A R)$ was 900 $\mu \mathrm{mol} \cdot \mathrm{m}^{-2} \cdot \mathrm{s}^{-1}$ with a $12-\mathrm{h}$ daylength. Plants were placed in the chamber to acclimate $48 \mathrm{~h}$ before the measurement. Assimilation and transpiration of each tree were measured in two independent experiments. In May 1994 (Expt. 1), carbon assimilation and transpiration were determined for six trees of each phenotype in a nonstressed state. Data were analyzed in a paired $t$ test design with six replications. In Sept. 1994 (Expt. 2) carbon assimilation and transpiration were determined for each phenotype, first measured in a nonstressed state; water was then withheld within the chamber for $2 \mathrm{~d}$ and measurements repeated to reflect the water-stressed condition. Leaf water potential was measured (three leaves/tree) on the $8^{\text {th }}$ mature leaf from the terminal at $1500 \mathrm{HR}$ for the nonstressed and water stressed sampling times. Data were analyzed in randomized complete-block design with six replications of four treatments. WUE was calculated as the mole ratio of net carbon assimilation to water transpired.

Greenhouse study. Following the growth chamber studies, an additional water stress study (Expt. 3) was conducted under greenhouse conditions of $32{ }^{\circ} \mathrm{C}$ daily maximum temperature, $\approx 70 \%$ daily maximum $\mathrm{RH}$, and $60 \%$ of daily incoming solar radiation. The apparent root surface water potential (ARSWP) (Jones, 1983) was calculated using the nonstressed standard type as the reference and comparing the willow-leaf stressed and nonstressed, and the standard stressed. Three plants of each phenotype were stressed by withholding water for $2 \mathrm{~d}$ prior to the measurement of stomatal conductance and leaf water potential used in the calculation. Leaf physiology measurements were made at $1500 \mathrm{HR}$ on the sampling day. Leaf number was counted on each tree, converted to leaf area, and used to normalize the ARSWP. Soil water potential was measured with a tensiometer. Data were analyzed as a randomized complete-block design with three replications of four treatments. Following the greenhouse studies, leaf impressions were made of four mid-shoot leaves/tree (Wilson et al., 1981). On each impression, stomatal number and aperture length were measured on 10 fields/leaf.

Field studies. Six trees each of the standard-leaf and the willow-leaf phenotype were planted in the field at a $3 \mathrm{~m}$ in row spacing using a paired arrangement, as in the growth chamber studies. The trees were maintained in the field for two growing seasons. For mea- 
surements of leaf length and branch diameter, 25 branches were selected and tagged on each of three willow-leaf trees and three standard-leaf trees. Leaf length measurements were made on leaf 5 and leaf 10 counting from the shoot apex (position 0). Leaf 5 in most cases was still expanding, whereas leaf 10 was fully expanded. Branch and petiole diameter measurements were made with digital calipers (Mitutoyo MTI Corp., Aurora, Ill.). Petiole diameter measurements were made at the petiole midsection; branch diameter measurements were made just below nodes of leaf 5 and 10 (current wood diameters) or $5 \mathrm{~cm}$ below the boundary between the current and previous year's growth (previous year's diameter). Leaf area was measured on 10 leaves per tree for leaf position 7 10. Leaf material for scanning electron microscopy (SEM) was collected from fieldgrown trees. Selected branches were taken into the laboratory and a second cut was made under water $\approx 7 \mathrm{~cm}$ above the original cut to prevent cavitation. The branches were kept in water at room temperature. Leaf surfaces were preserved through impressions (molds) and subsequent casts using the method of Williams et al. (1987) and Williams and Green (1988) with modifications suggested by Jernstedt et al. (1992). Epoxy resin casts were coated with gold/palladium and photographed on a Stereoscan model 120 SEM
(Cambridge Instruments, Cambridge, England) operated at $10 \mathrm{kV}$. Stomatal topography was viewed from leaf impressions. Visualization of plant surfaces with the mold and cast technique results in an accurate preservation of surface features reflected at the cellular level (Jernstedt et al., 1992; Williams and Green, 1988). Unlike standard SEM preservation techniques which can strip or distort some plant surface features, e.g. the cuticle, the present method allows examination of essentially intact surface features.

Thirty mid-shoot leaves per tree from each of six field-grown trees per phenotype were collected in July 1996 and May 1999, dried at $60{ }^{\circ} \mathrm{C}$, and analyzed for carbon discrimination $(\Delta)$ by Isotope Services (Los Alamos, N.M.). Isotopic discrimination was calculated according to Farquhar et al. (1989). The isotopic composition of carbon dioxide in air was assumed to be -7.8 parts per thousand (Francey et al., 1995). Data were analyzed using a paired $t$ test for each year.

Thirty randomly selected, fully expanded leaves per tree from each of 10 willow-leaf and 10 standard-leaf trees were collected in May 1999 from three seedling populations segregating for the willow-leaf character: BY92P2484 (willow-leaf) open-pollinated, BY93P4584 (willow-leaf) open-pollinated, and seedlings from the cross of 'Loring' $x$ willow-leaf selection BY90P3135. Leaves
$15-25 \mathrm{~mm}$ in width were collected as willowleaf types and leaves $30-40 \mathrm{~mm}$ in width were collected as standard-leaf types. Leaves were dried at $60{ }^{\circ} \mathrm{C}$, and analyzed for $(\Delta)$ by Isotope Services, as described above. Data were analyzed using a $t$ test.

\section{Results and Discussion}

The willow-leaf phenotype initially derived its name from the long, narrow leaves (Lesley, 1957). The willow-leaf phenotype of the present studies had longer (14.0 vs. $12.2 \mathrm{~cm})$, narrower leaves (1.7 vs. $3.4 \mathrm{~cm})$, less area per leaf ( 20.9 vs. $\left.42.5 \mathrm{~cm}^{2}\right)$ and per plant $\left(2.0 \mathrm{~m}^{2}\right.$ vs. $\left.3.1 \mathrm{~m}^{2}\right)$, and similar shoot diameter ( 2.9 vs. $3.2 \mathrm{~mm}$, nonsignificant) than the standard phenotype, respectively $(P$ $\leq 0.05)$. Stomatal aperture length $(28 \mathrm{~mm}$ for both) and stomatal density ( $197 \mathrm{vs.} 232 / \mathrm{mm}^{2}$ ) were not different for standard and willow types, respectively $(P \leq 0.05)$. The surface of the standard-leaf phenotype was rougher and more irregular than that of the willow-leaf phenotype (Fig. 1).

The difference in leaf area between standard and willow-leaf trees makes direct comparisons of assimilation and transpiration ambiguous. For this reason, WUE was calculated as a common basis of comparison. The WUE of willow-leaf trees was significantly greater than that of standard-leaf trees under
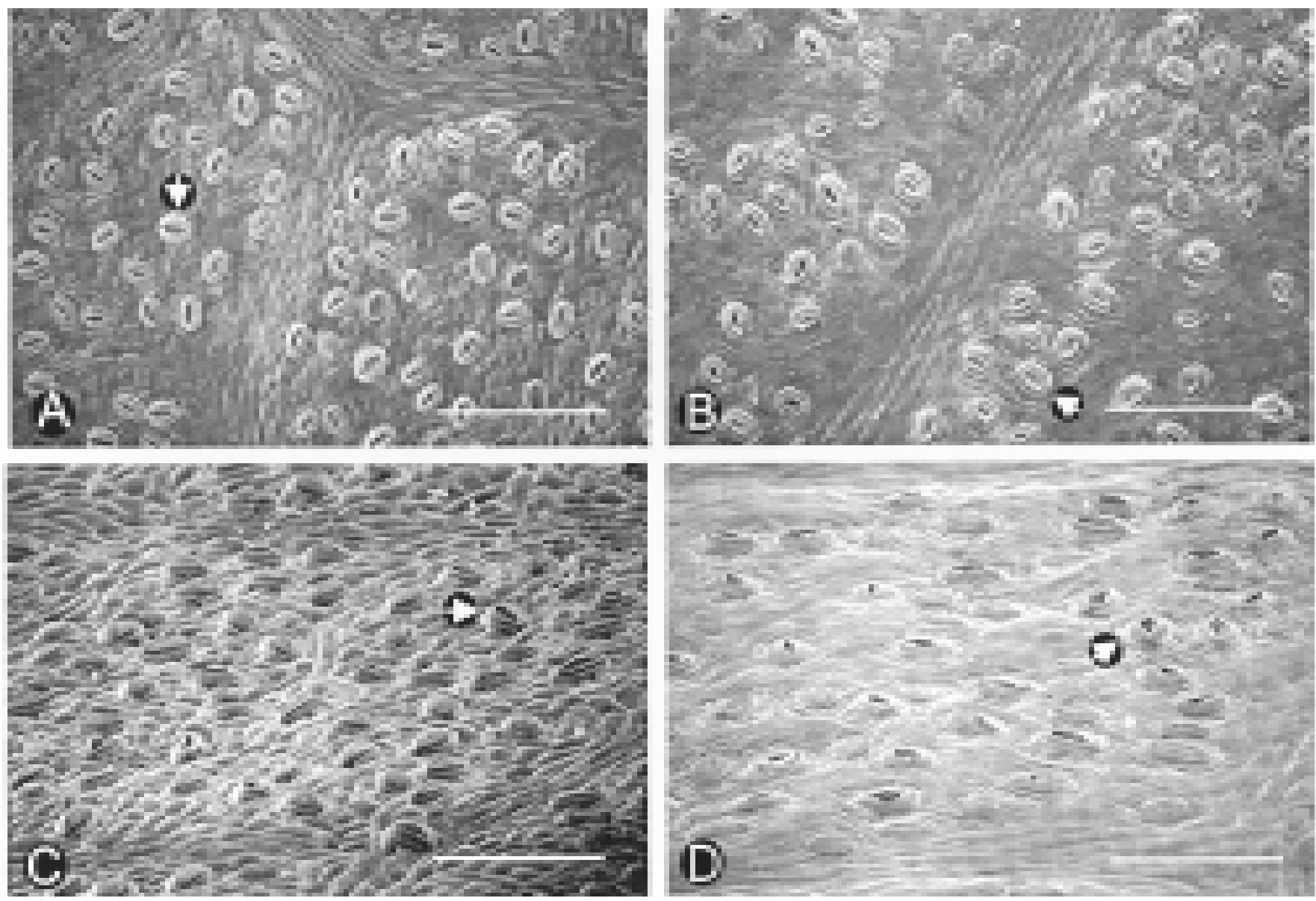

Fig. 1. Scanning electron microscopy of adaxial leaf surfaces of willow and standard-leaf peach phenotypes. (A) and (C): standard phenotype; (B) and (D): willow phenotype. Views in A and B are perpendicular to the surface; views in C and D are at an approximate $30^{\circ}$ angle to enhance the 'relief' of the photograph. Arrows mark examples of fully open stomata. Bar $=200 \mathrm{~mm}$. 
Table 1. Whole plant carbon assimilation, transpiration, water use efficiency (WUE) and leaf water potential for willow and standard-leaf peach trees in nonstressed and water-stressed conditions.

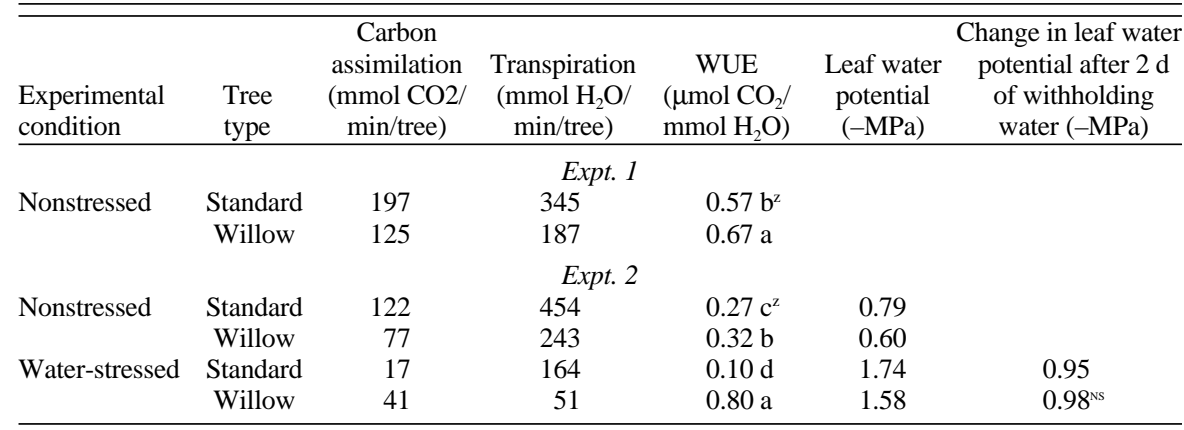

${ }^{\mathrm{z}}$ Mean separation within experiments and columns based on paired $t$ test $(P \leq 0.05)$ for Expt. $1, \mathrm{n}=6$ and protected Duncan's multiple tange test $P \leq 0.05$ for Expt. $2, \mathrm{n}=3$.

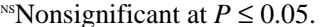

Table 2. Effect of water stress on apparent root surface water potential (ARSWP) and soil water potential for willow- and standard-leaf peach trees (Expt. 3).

\begin{tabular}{lcccc}
\hline $\begin{array}{l}\text { Experimental } \\
\text { condition }\end{array}$ & $\begin{array}{c}\text { Tree } \\
\text { type }\end{array}$ & $\begin{array}{c}\text { ARSWP } \\
(-\mathrm{MPa})\end{array}$ & $\begin{array}{c}\text { Leaf water } \\
\text { potential }(-\mathrm{MPa})\end{array}$ & $\begin{array}{c}\text { Soil water } \\
\text { potential (-MPa) }\end{array}$ \\
\hline Nonstressed & Standard & $0 \mathrm{a}^{\mathrm{z}}$ & $0.99 \mathrm{a}$ & $0.004 \mathrm{a}$ \\
& Willow & $0.52 \mathrm{~b}$ & $0.89 \mathrm{a}$ & $0.004 \mathrm{a}$ \\
Water-stressed & Standard & $1.77 \mathrm{~d}$ & $2.20 \mathrm{c}$ & $0.08 \mathrm{~b}$ \\
& Willow & $0.91 \mathrm{c}$ & $1.34 \mathrm{~b}$ & $0.09 \mathrm{~b}$
\end{tabular}

${ }^{\mathrm{z}}$ Mean separation within columns based on a protected Duncan's multiple tange test $P \leq 0.05, \mathrm{n}=3$.

both nonstressed and water-stressed conditions (Table 1). Shoot growth was occurring during Expt. 1 but ceased for Expt 2, and this may be the reason for the overall decrease in WUE for both tree types in Expt 2. In Expt 2, leaf water potential was measured for nonstressed and water-stressed trees. Overall, an equivalent $1 \mathrm{MPa}$ water-stress deficit developed in the water-stressed trees of both types. Under nonstressed conditions the willow-leaf phenotype had higher WUE that the standard-leaf phenotype. For similar plant water deficits, the WUE of the willow type was greater under water stress conditions than under nonstressed conditions, whereas the reverse was true for the standard-leaf phenotype.

Water stress studies evaluating the apparent root surface water potential (ARSWP) demonstrated that the willow type maintained a less negative ARSWP than did the standard-leaf type tree under similar soil deficit conditions (Table 2). While the nonstressed willow phenotype had an ARSWP $<0$, statistically different from the standard nonstressed trees, this reflects the inability of the normalization calculations of ARSWP to fully account for phenotypic differences such as hydraulic conductivity, since trees in both nonstressed treatments were well-watered and had similar leaf and soil water potentials. The relative differences between willow and standard types suggest that within the tree, the willow type develops less water potential gradient from the root to the leaf to drive water uptake and transpiration and that the willow-type tree is less coupled to the environment and therefore develops less water potential gradient to drive transpiration. Leaf topography does not indicate any morphological trait that would de-couple the willow- leaf phenotype from the aerial environment. In fact, the smooth nature of the cuticle suggests that boundary layer resistance should width would also reduce boundary layer resistance (Rosenberg et al., 1983). There are probably other morphological and biochemical traits related to the increased WUE of the willow-leaf phenotype beyond the external leaf morphology.

Willow-leaf isotopic discrimination $(\Delta)$ was significantly lower $(P \leq 0.001)$ than the standard-leaf type (16.84 vs. 18.20 in 1996 and 15.90 vs. 18.70 in 1999 , respectively) when tree were grown in the field without irrigation for two years (May-Sept. cumulative rainfall of 809 and $562 \mathrm{~mm}$, for 1996 and 1999, respectively). Others have demonstrated that a decrease in $\Delta$ is correlated with increased WUE (Bongi et al., 1994; Ehleringer, 1993; Farquhar and Richards, 1984; Johnson and Tieszen, 1993; Le Roux et al., 1996; Meinzer et al., 1993; White et al. 1990). Our data suggest that the willow-leaf chimerical mutation had better WUE than the standard-leaf type, based on isotopic discrimination of $\mathrm{CO}_{2}$ and water use studies in growth chambers. This work supports the concept of using $\Delta$ as a screening technique to identify improved WUE peach lines and confirms the work of Bongi et al. (1994).

In a population of peach seedlings exhibiting a range of leaf width from $15 \mathrm{~mm}$ to $>40$ $\mathrm{mm}$, the willow-leaf types had a reduced $\Delta$ compared to the standard-leaf types (17.8 vs. $18.2, P \leq 0.08)$. These data support the results of our detailed study of the willow-leaf chimera and suggest that WUE of peach trees, as indicated by reduced $\Delta$, can be improved by using the willow-leaf type in peach breeding programs. The performance of willow-leaf be reduced (Fig. 1) and the narrower leaf trees in terms of fruit production, fruit quality, fruit size, and biotic and abiotic stress resistance remains to be determined.

\section{Literature Cited}

Bongi, G., A. Palliotti, P. Rocchi, and G. Roselli. 1994. Evaluation of WUE in peach grafted on different interspecific hybrid rootstocks. Plant Physiol. Biochem. 32:149-157.

Ehleringer, J.R. 1993. Variation in leaf carbon isotope discrimination in Encelia farinosa: Implications for growth, competition and drought survival. Oecologia 95:340-346

Farquhar, G.D., J.R. Ehleringer, and K.T. Hubick. 1989. Carbon isotope discrimination and photosynthesis. Annu. Rev. Plant Physiol. Mol. Biol. 40:503-537.

Farquhar, G.D. and R.A. Richards. 1984. Isotopic composition of plant carbon correlates with water-use efficiency of wheat genotypes. Aust. J. Plant Physiol. 11:539-552.

Francey, U.J., P.P. Tans, C.E. Allison, I.G. Enting, J.W.C. White, and M. Troller. 1995. Changes in oceanic and terrestrial carbon uptake since 1982. Nature 373:326-330.

Glenn, D.M. and R. Scorza. 1992. Reciprocal grafts of standard and dwarf peach alter dry-matter partitioning and root physiology. HortScience 27:241-243.

Jernstedt, J.A., E.G. Cutter, E.M. Gifford, and P. Lu 1992. Angle meristem origin and development in Selaginalla martensii. Ann. Bot. 69: 351-363.

Johnson, R.C. and L.L. Tieszen. 1993. Carbon isotope discrimination, water relations and gas exchange in temperate grass species and accessions, p. 281-296. In: J.R. Ehleringer, A.E. Hall, and G.D. Farquhar (eds.). Stable isotopes and plant carbon-water relations. Academic Press, San Diego.

Jones, H.G. 1983. Estimation of an effective soil water potential at the root surface of transpiring plants. Plant, Cell \& Environ. 6:671-674.

Le Roux, D., W.D. Stock, W.J. Bond and D. Maphanga. 1996. Dry mass allocation, WUE and $\mathrm{d}^{13} \mathrm{C}$ in clones of Eucalyptus grandis, E. grandis Xcamaldulensis and E. grandis Xnitrens grown under two irrigation regimes. Tree Physiol. 16:497-502.

Lesley, J.W. 1957. A genetic study of inbreeding and of crossing inbred lines of peaches. Proc. Amer. Soc. Hort. Sci. 70:93-103.

Meinzer, F.C., G. Goldstein, and D.A. Grantz. 1993. Carbon isotope discrimination and gas exchange in coffee during adjustment to different soil moisture regimes, p. 327-345. In: J.R. Ehleringer, A.E. Hall, and G.D. Farquhar (eds.). Stable isotopes and plant carbon-water relations. Academic Press, San Diego.

Rosenberg, N.J., B.L. Blad, and S.B. Verma. 1983. Microclimate. The biological environment. $2^{\text {nd }}$ ed. Wiley. New York.

White, J.W., J.A. Castillo, and J. Ehleringer. 1990. Associations between productivity, root growth, and carbon isotope discrimination in Phaseolus vulgaris under water deficit. Austral. J. Plant Physiol. 17:189-198.

Williams, M.H. and P.B. Green. 1988. Sequential scanning electron microscopy of a growing plant meristem. Protoplasma 147:77-79.

Williams, M.H., M. Vesk, and M.G. Mullins. 1987. Tissue preparation for scanning electron microscopy of fruit surfaces: Comparison of fresh and cryopreserved specimens and replicas of banana peel. Micron and Microscopica Acta 18:27-31.

Wilson, C.L. Wilson, P.L. Pusey, and B.E. Otto. 1981. Plant epidermal sections and imprints using cyanoacrylate adhesives. Can. J. Plant Sci. 61:781-782. 